\title{
Allelopathic and autotoxicity effects of barley (Hordeum vulgare L. ssp. vulgare ) root exudates
}

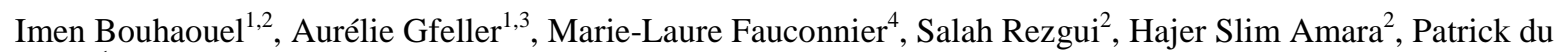 \\ $\operatorname{Jardin}^{1}$ \\ ${ }^{1}$ Plant Biology Laboratory, Gembloux Agro-Bio Tech, University of Liège, 2 Passage de Déportés, 5030 Gembloux, Belgium \\ ${ }^{2}$ Genetics and Plant Breeding Laboratory, Department of Agronomy and Plant Biotechnology, National Agronomic Institute of Tunisia, 43 \\ Charles Nicolle Street, 1082 Tunis Mahragene, Tunisia \\ ${ }^{3}$ Swiss Federal Research Station Agroscope Changins Wädenswil AC, 1260 Nyon, Switzerland \\ ${ }^{4}$ General and Organic Chemistry Laboratory, Gembloux Agro-Bio Tech, University of Liège, 2 Passage de Déportés, 5030 Gembloux, \\ Belgium
}

\begin{abstract}
The allelopathic activity of barley (Hordeum vulgare L. ssp. vulgare) root exudates was studied by comparing their effects on seedling establishment in barley itself and in two weed species, Bromus diandrus Roth, and Lolium rigidum Gaudin, using an original laboratory protocol, named 'seed-after-seed'. In this protocol, the donor and the receiver species of water-soluble allelochemicals are grown one after the other in the same dishes, in conditions reducing resource competition between both species. Growth of all receptive species (weeds and barley) was inhibited in a dose-dependent manner, when using increasing barley seed densities $(0,8$, 19 and 25 seeds per Petri dish). In our conditions, the barley varieties and landraces exhibited different allelopathic activities against weeds or barley. The allelopathic potential of the barley root exudates was also dependent on the receiver species. Indeed, the released allelochemicals proved to be more toxic against the weed plants than on barley itself. Furthermore, the toxicity of the allelochemicals increased after their release by roots, between day 0 and day 6 . These allelochemicals might contribute to the plant community dynamics and their usefulness as bio-herbicides deserves further consideration.
\end{abstract}

Keywords : Allelopathy ; Hordeum vulgare L. ssp. vulgare ; Root exudates ; Competition ; Allelochemical toxicity ; Weed management

\section{Introduction}

In Tunisia, great brome (Bromus diandrus Roth., syn. Bromus rigidus Roth. subsp. gussonii Parl.) and ryegrass (Lolium rigidum Gaudin) are troublesome grassy weeds that are largely distributed in cereal crops (Souissi et al. 2001; Ben Haj Salah et al. 2005). Field surveys conducted in the north of Tunisia in 2000 revealed that $82 \%$ of the prospected areas were highly infested by great brome (150-400 plants $\left.\mathrm{m}^{2}\right)$.

The weed reduced wheat yield by $20-50 \%$ and up to $80 \%$ in heavily infested areas, cost to growers up to $\$ 1.6$ million year $^{-1}$ (Souissi et al. 2000, 2001). Great brome is a very competitive weed in the wheat crop by its adaptive life cycle characteristics, especially by earliness in the development cycle, staggered germination, high tillering capacity, and acceleration in the shooting elongation stage (Ben Haj Salah et al. 2005). Furthermore, the invasion of cereal crops by this weed is also favored by monoculture, the reduction of the cultural techniques and the ineffectiveness of the conventional control methods, especially in the absence of a selective and effective herbicide against this weed (Souissi et al. 2000). Furthermore, in 1996, a first report has showed that ryegrass $(L$. rigidum) had evolved resistance to graminicides that were highly effective for its post-emergence control in Tunisian cereal crops (Gasquez 2000; Souissi et al. 2004).

Allelopathy, including the direct or indirect harmful or beneficial effects of one plant as a donor plant on another as receiver plant by the production of chemical compounds that escape into the environment (Rice 1984), may provide alternative biological weed control. Indeed, there is an increasing interest in the weed suppressive ability of crops for both organic and conventional farming systems (Mason and Spaner 2006). Cereal crop plants, such as wheat (Lodhi et al. 1987; Wu et al. 2000a, b), barley (Overland 1966; Liu and Lovett 1993b; Fujii 2001) and rice (Olofsdotter et al. 1999), have been shown to produce allelochemicals with a capacity to reduce growth of other plant species. 
Barley (Hordeum vulgare L. ssp. vulgare) is well known for its allelopathic compounds. Seeds (Liu and Lovett 1993a), residues (Gubbels and Kenaschuk 1989) or root exudates of this species (Bertholdsson 2004) have been examined for their allelopathic potential against some crop species or weeds. Baghestani et al. (1999) and Ma et al. (1999) showed that barley germplasm contained a wider variety of allelopathic substances than wheat germplasm, including phenolic acids, making barley a nice crop model for the study of allelopathy.

Barley was also found to be autotoxic (Ben-Hammouda et al. 2002), which can be described as an intraspecific form of allelopathy, by decreasing its own seed germination or seedling development (Putnam 1985). These studies concluded that barley is prone to a high 'allelopathic risk' in barley-barley cropping sequences (Oueslati et al. 2005). Autotoxicity in barley crops was described as the repressive effect of their residues, but whether root exudates of intact plants also show some allelopathic effect on barley growth was never studied. Furthermore, to our knowledge, the alloinhibition and autoinhibition activities were never compared by using protocols intended to this aim.

Considerable genetic variation in the allelopathic activity has been found in barley (Hoult and Lovett 1993; Baghestani et al. 1999; Chon and Kim 2004; Oveisi et al. 2008). This variability is proposed to be related to variations in the profiles and quantities of secondary metabolites (Ben-Hammouda et al. 1995). Untill now only 44 compounds belonging to different chemical classes (phenolics, alkaloids, cyanoglucosides, polyamines etc.) have been identified as potential allelochemicals that contribute to the allelopathic effectiveness of barley (Kremer and Ben-Hammouda 2009). The two alkaloids, gramine and hordenine, were the first allelochemicals proposed to explain the allelopathic effects of barley (Overland 1966; Liu and Lovett 1993b).

One limitation of allelopathy research, when using living plants, is the use of inadequate experimental designs. Indeed, plant-to-plant interference is a complex combination of competition for water, light and nutrients and of allelopathic chemicals interactions (Qasem and Hill 1989). Based on these considerations, the allelopathic potential of Tunisian barley root compounds was tested according to two experimental protocols, namely the 'seed-to-seed' where seeds of the allelochemical-donor species are grown together with the receiver species, and a new bioassay named 'seed-after-seed' where the donor and the receiver species of allelochemicals are grown sequentially, minimizing resource competition.

In this study, we addressed the following questions: (a) is the seedling establishment of great brome and ryegrass affected by barley root exudates? (b) do barley root exudates affect barley and weed plants to a similar or contrasting extent? and (c) do the different Tunisian genotypes of barley exhibit the same or different allelopathic potential?

\section{Materials and methods}

\section{Plant materials}

The seeds of five Tunisian barley (Hordeum vulgare L. ssp. vulgare), including three modern varieties ('Manel', 'Rihane' and Tej') and two landraces ('Ardhaoui' and 'Arbi'), and a Saudi Arabian barley landrace ('Saudi') were obtained from the National Agronomic Institute of Tunisia. Seeds of great brome (B. diandrus Roth.) and ryegrass (L. rigidum Gaudin) were collected from infested sites (between 36 $42^{\prime} 07.0^{\prime \prime} \mathrm{N}, 9^{\circ} 12^{\prime} 46.3^{\prime \prime} \mathrm{E}$ and $\left.36^{\circ} 41^{\prime} 00.2^{\prime \prime} \mathrm{N}, 9^{\circ} 13^{\prime} 09.8^{\prime \prime} \mathrm{E}\right)$ in the North of Tunisia, more specifically in the region of Beja.

\section{Sterilization and pre-germination}

All the seeds were surface-sterilized to avoid microbial contamination potentially influencing the bioavailability of allelochemicals (Inderjit 2005). Briefly, the barley and ryegrass seeds were immersed in $\mathrm{H}_{2} \mathrm{SO}_{4}(50 \% \mathrm{v} / \mathrm{v})$ for $1 \mathrm{~h}$ and washed five times in sterile double distilled water. Seeds were subsequently shaken in $\mathrm{AgNO}_{3}(1 \% \mathrm{w} / \mathrm{v})$ at $200 \mathrm{rpm}$ for $20 \mathrm{~min}$ and rinsed successively with $\mathrm{NaCl}(1 \% \mathrm{w} / \mathrm{v})$, sterile DD water, $\mathrm{NaCl}(1 \% \mathrm{w} / \mathrm{v})$ and five times with sterile DD water (Lanoue et al. 2010).

Great brome seeds were sterilized according to Wu et al. (2000b). The great brome seeds were surface-sterilized by soaking the seeds in ethanol $(70 \% \mathrm{v} / \mathrm{v})$ for $2.5 \mathrm{~min}$ and rinsed four times with sterile DD water. Seeds were then soaked in sodium hypochlorite $(2.5 \% \mathrm{v} / \mathrm{v})$ solution for $15 \mathrm{~min}$ followed by five rinses in sterile DD water. After sterilization, barley and weed seeds were pre-germinated on moist sterile filter paper in darkness at $22{ }^{\circ} \mathrm{C}$ for $24 \mathrm{~h}$.

\section{'Seed-to-seed' experimental protocol}


The allelopathic activity of germinating barley seeds was bioassayed on filter paper $(12-15 \mu \mathrm{m})$ in a $90 \mathrm{~mm}$ diameter Petri dish moistened with $4 \mathrm{ml}$ of sterile distilled water. Pre-germinated barley seeds were uniformly selected and evenly distributed on the Petri dish with three densities (8,19 and 25 seeds per Petri dish).

Thereafter, ten pre-germinated seeds of each weed ( $B$. diandrus or L. rigidum) were placed regularly between the donor seeds. A treatment without barley seed was used as control. The Petri dishes were sealed and maintained in a growth chamber at $22{ }^{\circ} \mathrm{C}$ in the dark. To minimize competition for water, water losses were aseptically compensated every day. The amount of the added water was estimated by weight difference of the Petri dishes between two successive days after removing seedlings of barley and weeds. After five days of growth, the weed seedlings' radicle and coleoptile lengths were measured. The bioassay was arranged as a completely randomized block design with four replicates for each treatment and repeated twice for each weed species.

\section{'Seed-after-seed' experimental protocol}

In order to minimize competition for water and/or for air between developing seedlings and to determine the effect of water-soluble allelochemicals of barley roots, a new laboratory bioassay was developed and named 'seed-after-seed' protocol. The pre-germinated barley seeds (8, 19 and 25 seeds per dish) were placed in a Petri dish in the same conditions as in the 'seed-to-seed' protocol. After five days, barley seedlings were removed and replaced by ten pre-germinated weed seeds (B. diandrus or L. rigidum). The Petri dishes were placed back in the growth chamber and the lost water was compensated daily as previously described. The experimental set-up was identical to that mentioned above. The radicle and coleoptile lengths of weed seedlings were recorded after five days of growth.

For the bioassay conducted with barley, pre-germinated barley seeds were used both as donors and receivers, using the same genotype. The experiment was performed with four replicates for each treatment.

\section{Stability of barley allelochemicals}

To analyze the possible sources of the differences between 'seed-to-seed' and 'seed-after-seed' results, the stability of the barley root allelochemicals presumably released on the filter paper was studied. In this bioassay, 'Ardhaoui' barley landrace was chosen as the donor species based on its high allelopathic potential against weeds. After five days, barley seedlings ( 25 seeds per dish) were removed from Petri dishes and replaced by ten pregerminated weed seeds (B. diandrus or L. rigidum) after 0, 2, 4 and 6 days. A randomized complete block design with four replicates was used.

\section{Statistical analysis}

All experimental data were subjected to analysis of variance using PROC MIXED of SAS package (SAS V9.1) and the subroutine PDMIX 800.SAS to compare the interaction means and main effects including Least Significant Difference (LSD) at a $5 \%$ level of probability.

\section{Results}

\section{Effect of the barley root allelochemicals on weed seedling establishment}

'Seed-to-seed' experimental protocol

In the 'seed-to-seed' assay, B. diandrus and L. rigidum growth was reduced after five days (Figs. 1, 2). Weed radicle growth inhibition $(F=176.91, \mathrm{df}=6,133, P<0.001 ; F=148.32$, df $=6,133, P<0.001$ for $B$. diandrus and $L$. rigidum, respectively) and coleoptile growth inhibition $(F=17.13, \mathrm{df}=6,133, P<0.001 ; F=8.95, \mathrm{df}=$ $6,133, P<0.001$ for $B$. diandrus and $L$. rigidum, respectively) were significant compared to the control from the lowest applied 'dose' (i.e. seed density) of barley, except for the coleoptile growth of 'Manel' in the condition of 8 and 19 barley seeds per dish. The results also showed that this effect depended on barley dose as barley (cv. 'Ardhaoui') density increased from 8 to 19 and 25 seeds per dish, radicle growth inhibition increased linearly and ranged from 67 to $74 \%$ for B. diandrus and from 55 to $65 \%$ for L. rigidum. Radicle growth inhibition after five days (inhibition average of $B$. diandrus and L. rigidum by the six barley genotypes were 71 and $61 \%$, respectively when using 25 barley seeds per dish) was higher than coleoptile growth inhibition (inhibition average of B. diandrus and L. rigidum by the six barley genotypes were 42 and $18 \%$, respectively when using 25 barley seeds per dish). 
Fig. 1 Radicle and coleoptile growth inhibition (\%) of B. diandrus seedlings after five days exposed to barley seedlings allelochemicals according to the 'seed-to-seed' experimental protocol. Since interaction is not significant between seed density and genotypes for radicle growth inhibition parameter, the two factors are illustrated separately into two graphics. Graph bars (mean $\pm S E$ ) with the same letter are not significantly different $(P>0.05 ;$ LSD test $)$
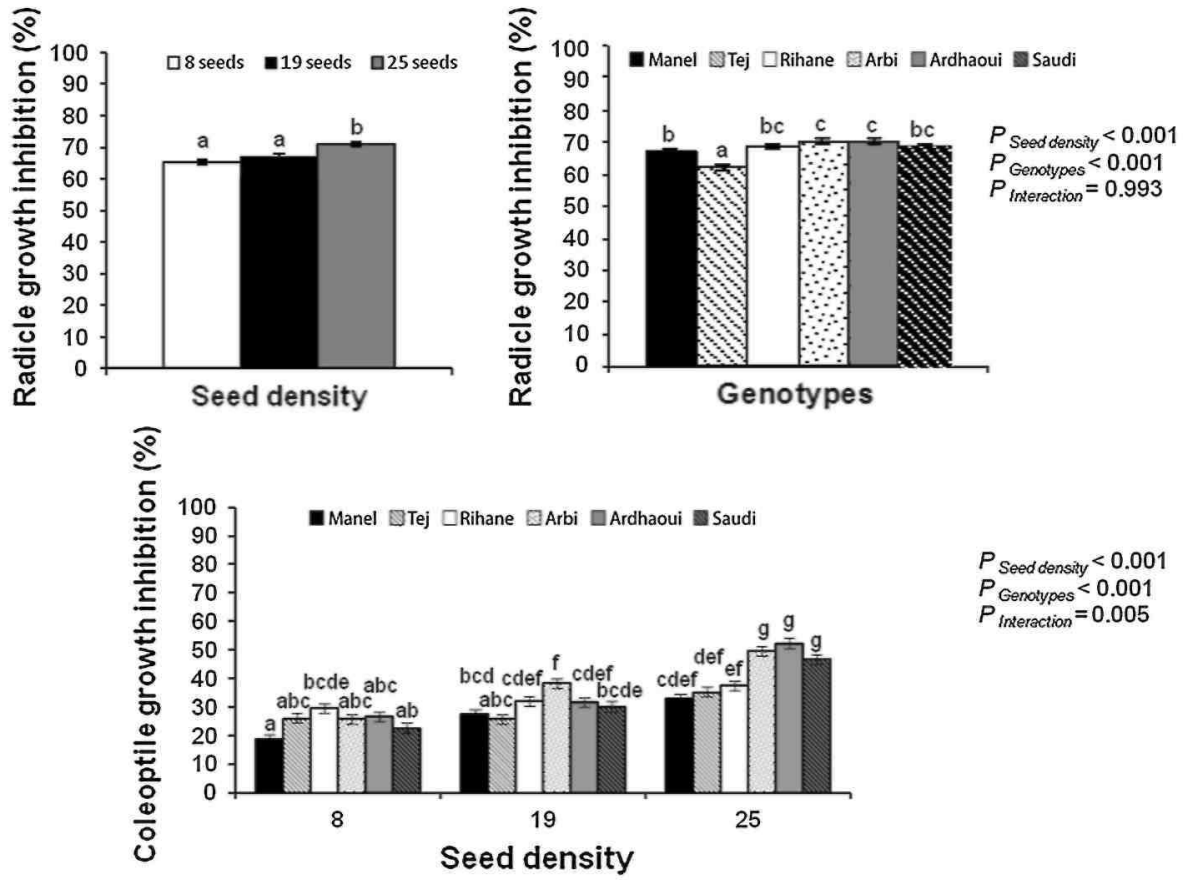

$P$ Genotypes $<0.001$

Seed density

Fig. 2 Radicle and coleoptile growth inhibition (\%) of L. rigidum seedlings after five days exposed to barley seedlings allelochemicals according to the 'seed-to-seed' experimental protocol. Since interaction is not significant between seed density and genotypes for radicle and coleoptile growth inhibition parameters, the two factors are illustrated separately into two graphics. Graph bars (mean $\pm S E$ ) with the same letter are not significantly different ( $P>0.05$; LSD test)
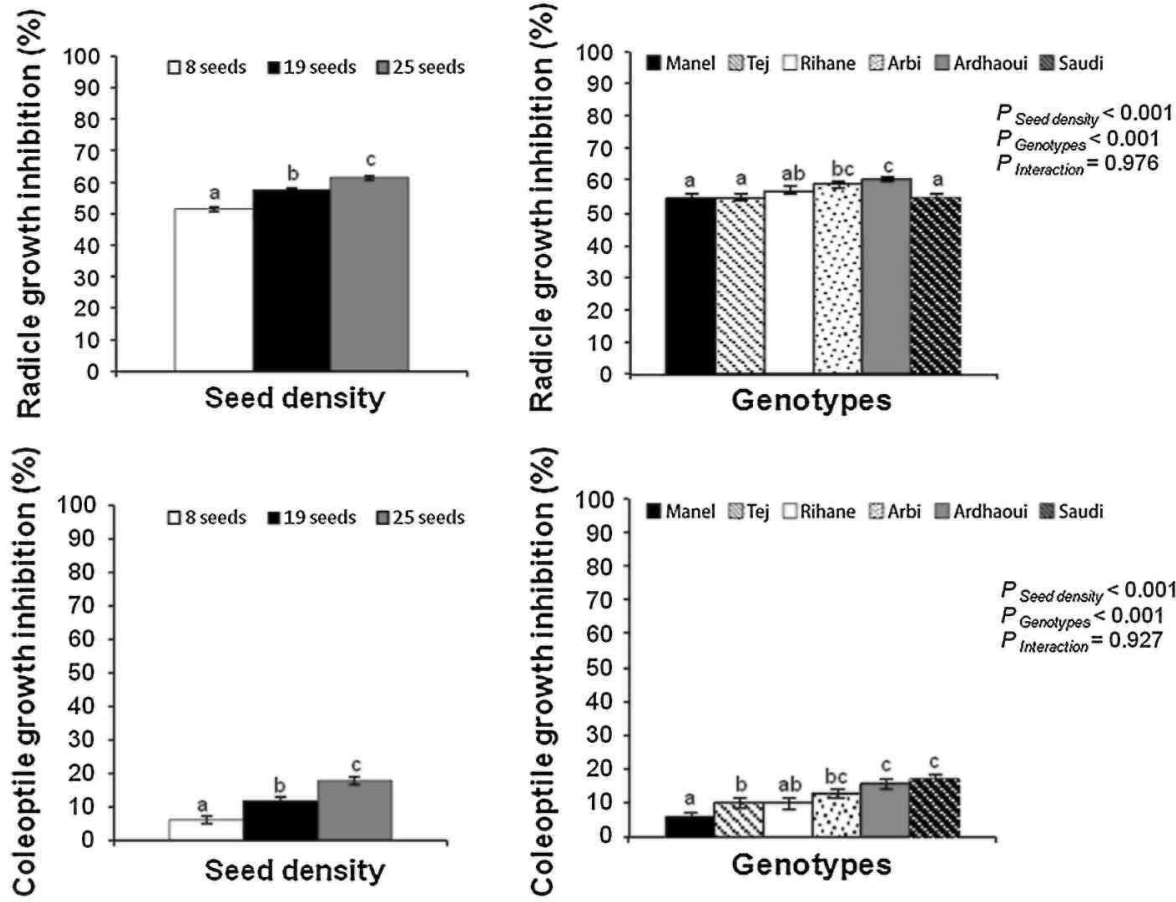
Both weed species (B. diandrus and $L$. rigidum) responded differentially to the allelopathic compounds of barley $(F=5.00, \mathrm{df}=5,126, P<0.001 ; F=5.90, \mathrm{df}=5,126, P<0.001$ for radicle and coleoptile growth inhibition of $B$. diandrus and $F=3.49, \mathrm{df}=5,126, P<0.001 ; F=3.66, \mathrm{df}=5,126, P<0.001$ for radicle and coleoptile growth inhibition of $L$. rigidum). Indeed, inhibition rates of great brome ranged from 65 to $74 \%$ for radicle growth, depending on the barley genotype, and from 33 to $52 \%$ for coleoptile growth, when using 25 barley seeds per dish (Figs. 1, 2). Considering the different barley genotypes, the inhibitory activity of 'Ardhaoui' and 'Arbi' was higher (74 and $74 \%$ respectively for radicle growth inhibition of great brome using 25 barley seeds per dish) than that of 'Manel' and 'Tej' (65 and $69 \%$ respectively for radicle growth inhibition of great brome using 25 barley seeds per dish).

\section{'Seed-after-seed' experimental protocol}

For the 'seed-after-seed' method, the same general trend was observed (Figs. 3, 4). The root allelochemicals had a significant inhibitory activity on root growth $(F=43.66$, df $=6,57, P<0.001 ; F=45.57$, df $=6,57, P<0.001$ for $B$. diandrus and L. rigidum, respectively) of weeds when compared to the control from the lowest applied 'dose' of barley. However, this effect was not significant for coleoptile growth of $B$. diandrus $(F=0.22$, df $=6$, $57, P=0.962$ ) except for 'Ardhaoui' and 'Arbi' in conditions of 8 barley seeds per dish but significant for coleoptile growth of $L$. rigidum $(F=5.93, \mathrm{df}=6,57, P<0.001)$ except for 'Manel' in conditions of 8 barley seeds per dish and 'Tej' for all densities. The inhibition rates were higher on root growth (inhibition average of $B$. diandrus and $L$. rigidum by the six barley genotypes were 52 and $50 \%$, respectively when using 25 barley seeds per dish) than on coleoptile growth (inhibition average of $B$. diandrus and L. rigidum by the six barley genotypes were 16 and $10 \%$, respectively when using 25 barley seeds per dish). The barley varieties and landraces exhibited a differential allelopathic activity against $L$. rigidum $(F=6.24, \mathrm{df}=5,54, P<0.001 ; F=3.71, \mathrm{df}=5$, $54, P=0.004$ for radicle and coleoptile growth inhibition, respectively). For example, the six barley genotypes reduced radicle growth of $L$. rigidum by $45-54 \%$ and coleoptile by 6-18 \% when using 25 barley seeds per dish. This effect was also significant on radicle growth $(F=3.93, \mathrm{df}=5,54, P=0.002)$ when testing the $B$. diandrus. However, the different genotypes showed no significant difference in the inhibition of coleoptile growth $(F=$ $0.30, \mathrm{df}=5,54, P=0.387$ ). 'Ardhaoui' and 'Arbi', displayed the highest inhibition rates (58 and $55 \%$ respectively for radicle growth inhibition of great brome using 25 barley seeds per dish). The lowest radicle inhibition rates were obtained with 'Tej' and 'Manel' (47 and $51 \%$ respectively for radicle growth inhibition of great brome using 25 barley seeds per dish).

When comparing the 'seed-to-seed' and the 'seed-after-seed' protocols, the inhibitory effect of the barley radicle compounds was higher in the 'seed-to-seed' protocol (inhibition average of radicle growth of $B$. diandrus and $L$. rigidum by the six barley genotypes were 71 and $61 \%$, respectively when using 25 barley seeds per dish) than in the 'seed-after-seed' protocol (inhibition average of radicle growth of B. diandrus and L. rigidum by the six barley genotypes were 52 and $50 \%$, respectively when using 25 barley seeds per dish) experimental protocol (Figs. 3, 4) and were significantly different for both weeds (all $P<0.001$; Tables 1, 2).

\section{Effect of the barley root allelochemicals on barley seedling establishment}

Radicle and coleoptile growth of barley declined with increasing seed density (8, 19 and 25 seeds per dish; Fig. 5). The self-inhibitory effect of barley was significant compared to the control (Table 3) except for the coleoptile growth of 'Manel' and 'Saudi' in the condition of 8 barley seeds per dish. This effect was more pronounced on radicle (inhibition average by the six barley genotypes using 25 barley seeds per dish was $19 \%$ ) than on coleoptile growth (inhibition average by the six barley genotypes using 25 barley seeds per dish was $11 \%$ ). The barley genotypes differed in varietal inhibition only on radicle $(F=8.49$, df $=5,54, P<0.001)$ and not on coleoptile growth $(F=0.58, \mathrm{df}=5,54, P=0.621)$. Both barley landraces, 'Arbi' and 'Ardhaoui', exhibited the highest growth inhibition (26 and $24 \%$ respectively for radicle growth inhibition using 25 barley seeds per dish). However, 'Manel' and 'Tej' showed the lowest growth inhibition (13 and $16 \%$ respectively for radicle growth inhibition using 25 barley seeds per dish). 
Fig. 3 Radicle and coleoptile growth inhibition (\%) of B. diandrus seedlings after five days exposed to barley seedlings allelochemicals according to the 'seed-after-seed' experimental protocol. Since interaction is not significant between seed density and genotypes for radicle and coleoptile growth inhibition parameters, the two factors are illustrated separately into two graphics. Graph bars (mean \pm SE) with the same letter are not significantly different $(P>0.05 ;$ LSD test)
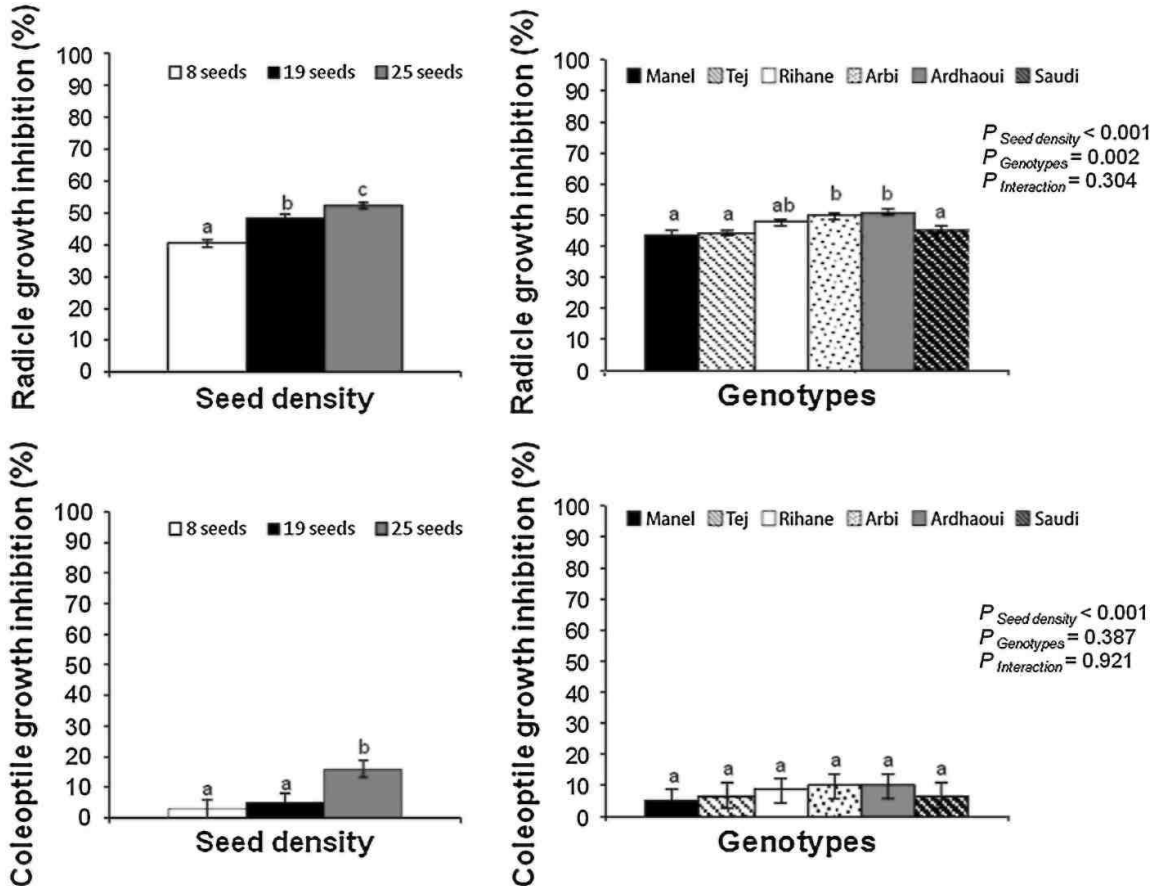

Fig. 4 Radicle and coleoptile growth inhibition (\%) of L. rigidum seedlings after five days exposed to barley seedlings allelochemicals according to the 'seed-after-seed' experimental protocol. Since interaction is not significant between seed density and genotypes for coleoptile growth inhibition parameter, the two factors are illustrated separately into two graphics. Graph bars (mean $\pm S E)$ with the same letter are not significantly different $(P>0.05 ;$ LSD test $)$
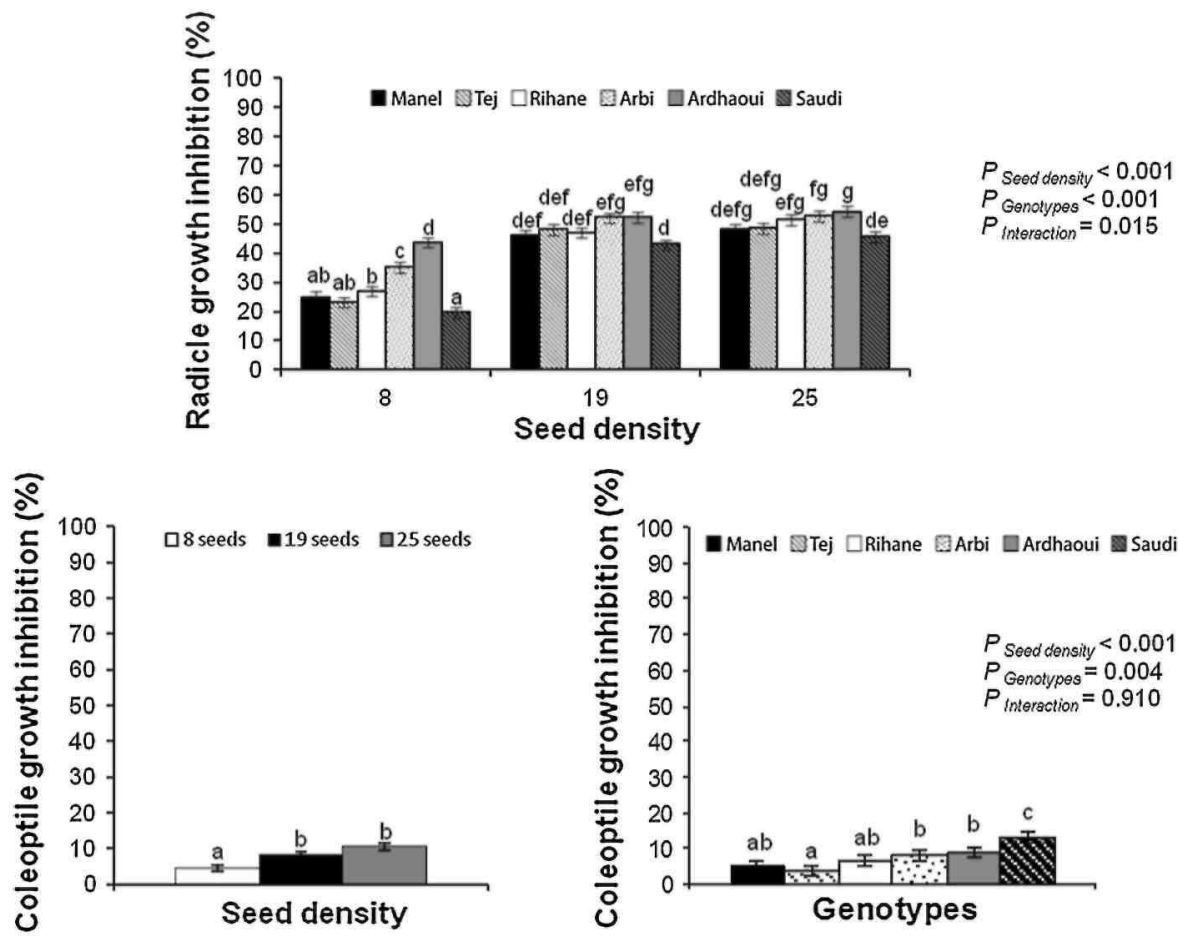
Table 1 Analysis of variance (ANOVA) in radicle and coleoptile length of B. diandrus among different treatments of radicle exudates of barley

\begin{tabular}{lcccccc}
\hline Factors & \multicolumn{3}{c}{ Radicle length } & \multicolumn{3}{c}{ Coleoptile length } \\
\cline { 2 - 7 } & df & $F$ & $P$ & df & $F$ & $P$ \\
\hline G & 5 & 5.26 & $<0.001$ & 5 & 1.99 & 0.086 \\
$\mathrm{D}$ & 2 & 28.15 & $<0.001$ & 2 & 23.53 & $<0.001$ \\
$\mathrm{P}$ & 1 & 436.56 & $<0.001$ & 1 & 176.60 & $<0.001$ \\
$\mathrm{D} \times \mathrm{P}$ & 2 & 4.64 & 0.012 & 2 & 0.56 & 0.574 \\
$\mathrm{G} \times \mathrm{P}$ & 5 & 0.76 & 0.580 & 5 & 0.42 & 0.833 \\
$\mathrm{G} \times \mathrm{D}$ & 10 & 0.53 & 0.866 & 10 & 0.41 & 0.938 \\
$\mathrm{G} \times \mathrm{D} \times \mathrm{P}$ & 10 & 0.47 & 0.905 & 10 & 0.48 & 0.899 \\
Error & 198 & & & 198 & & \\
Total & 233 & & & 233 & & \\
\hline$G$ ger & & & & & &
\end{tabular}

$G$ genotype, $D$ density, $P$ experimental protocol

Table 2 Analysis of variance (ANOVA) in radicle and coleoptile length of L. rigidum among different treatments of radicle exudates of barley

\begin{tabular}{lcccccc}
\hline Factors & \multicolumn{3}{c}{ Radicle length } & \multicolumn{3}{c}{ Coleoptile length } \\
\cline { 2 - 7 } & df & $F$ & $P$ & df & $F$ & $P$ \\
\hline G & 5 & 8.78 & $<0.001$ & 5 & 7.32 & $<0.001$ \\
D & 2 & 88.24 & $<0.001$ & 2 & 18.56 & $<0.001$ \\
$\mathrm{P}$ & 1 & 201.18 & $<0.001$ & 1 & 14.44 & $<0.001$ \\
$\mathrm{D} \times \mathrm{P}$ & 2 & 15.38 & $<0.001$ & 2 & 1.40 & 0.249 \\
$\mathrm{G} \times \mathrm{P}$ & 5 & 1.79 & 0.115 & 5 & 0.70 & 0.625 \\
$\mathrm{G} \times \mathrm{D}$ & 10 & 0.79 & 0.640 & 10 & 0.14 & 0.993 \\
$\mathrm{G} \times \mathrm{D} \times \mathrm{P}$ & 10 & 0.67 & 0.748 & 10 & 0.44 & 0.926 \\
Error & 198 & & & 198 & & \\
Total & 233 & & & 233 & & \\
\hline G & & & & & &
\end{tabular}

G genotype, D density, P experimental protocol

Fig. 5 Radicle and coleoptile growth inhibition (\%) of barley seedlings after five days exposed to its own seedlings allelochemicals according to the 'seed-after-seed' experimental protocol. Since interaction is not significant between seed density and genotypes for radicle and coleoptile growth inhibition parameters, the two factors are illustrated separately into two graphics. Graph bars (mean $\pm S E)$ with the same letter are not significantly different ( $P>0.05 ;$ LSD test)
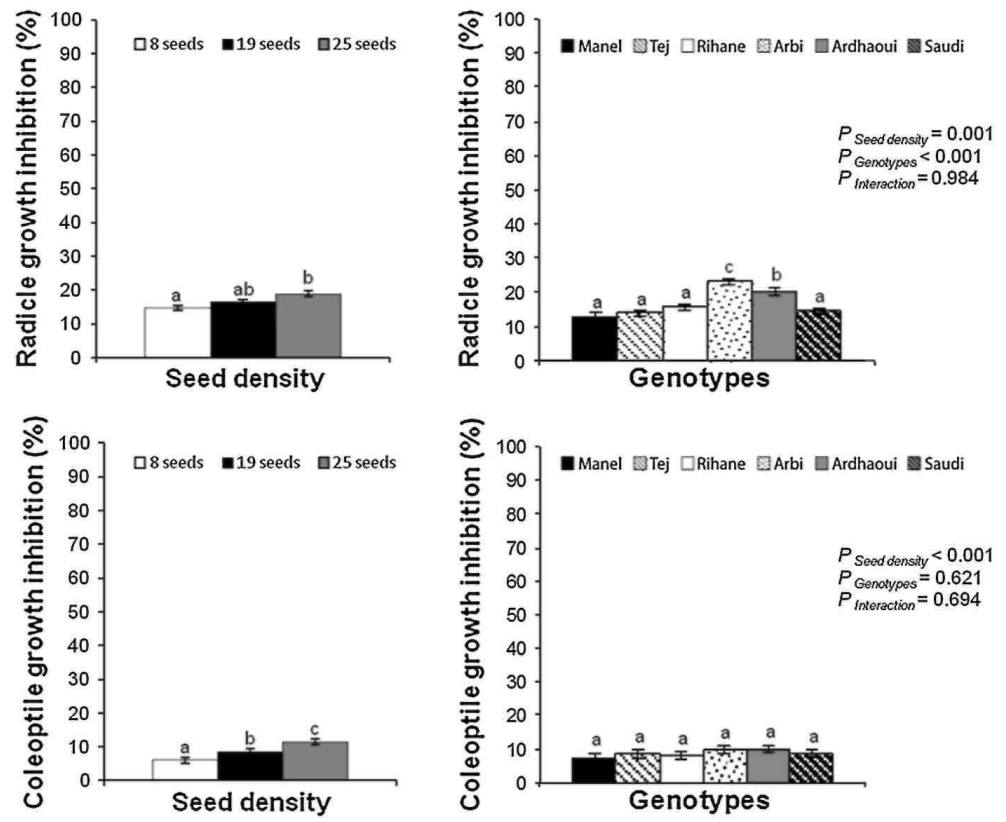
Table 3 Analysis of variance (ANOVA) in radicle and coleoptile length of different barley genotypes treated with radicle exudates of the same genotype

\begin{tabular}{|c|c|c|c|c|c|c|}
\hline Factors & Manel & Tej & Rihane & Arbi & Ardhaoui & Saudi \\
\hline \multicolumn{7}{|c|}{ Radicle length } \\
\hline$F$ & 9.08 & 9.85 & 15.31 & 35.89 & 19.22 & 11.59 \\
\hline $\mathrm{df}$ & 3,57 & 3,57 & 3,57 & 3,57 & 3,57 & 3,57 \\
\hline$P$ & $<0.001$ & $<0.001$ & $<0.001$ & $<0.001$ & $<0.001$ & $<0.001$ \\
\hline \multicolumn{7}{|c|}{ Coleoptile length } \\
\hline$F$ & 3.03 & 3.97 & 4.33 & 5.77 & 7.97 & 7.19 \\
\hline df & 3,57 & 3,57 & 3,57 & 3,57 & 3,57 & 3,57 \\
\hline$P$ & 0.031 & 0.009 & 0.006 & 0.001 & $<0.001$ & $<0.001$ \\
\hline
\end{tabular}

\section{Stability of barley allelochemicals}

The results indicated a change in allelochemical toxicity of 'Ardhaoui' over time (Fig. 6). For B. diandrus, the inhibitory activity of allelochemicals towards radicle and coleoptile growth increased from day 0 to day 6 after removal of the barley seeds. This increase in inhibitory activity over time was greater for coleoptile (38\% from day 0 to day 6 ) than for radicle growth (29\%). The same trend was obtained for L. rigidum (49\% of increase of inhibitory effect on coleoptile, and $43 \%$ of increase of inhibitory effect on radicle, from day 0 to day 6 ).

\section{Discussion}

Plant-plant interference may involve competition for limited resources but also allelopathic phenomena in which toxic organic compounds are released into the environment (Rice 1984). The relative importance of allelopathy and competition in plant-plant interactions has been debated but seldom tested (Fuerst and Putnam 1983; Nilsson 1994; Weidenhamer 1996; Ridenour and Callaway 2001), primarily because it is difficult to separate the effects of each phenomenon (Qasem and Hill 1989), hampering research on allelopathy in natural and cultivated plants. Multiple studies have found evidence for the existence of 'seed-to-seed' allelopathic effects by seed leachate or root exudates (Liu and Lovett 1993a; Kushima et al. 1998; Laterra and Bazzalo 1999; Zhang et al. 2011), but in most cases this experimental protocol does not exclude, on one hand, the effect of competition, and on the other hand, the possible effect of volatile organic compounds (VOCs), known to participate in plant communication and interactions (Ninkovic 2003; Kellner et al. 2010; Gfeller et al. 2013; Fiers et al. 2013).

Fig. 6 Evolution of barley allelochemicals toxicity over time on the growth of B. diandrus (a) and L. rigidum (b). The plotted percentages represent the percentages of increase in the inhibitory activity of allelochemicals for the different times after the removal of barley seedlings and are calculated as ((radicle or coleoptile length in $d=$ 0 -radicle or coleoptile length in $d=2,4$ or 6$)$ /radicle or coleoptile length in $d=0) \times 100$. Graph bars (mean \pm $S E)$ with the same letter are not significantly different $(P>0.05 ; L S D$ test $)$
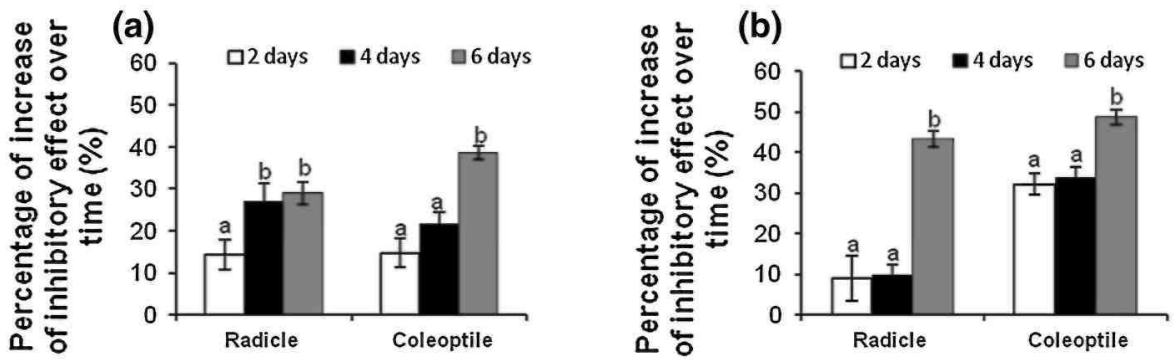

The present study showed that the inhibitory effect of the compounds emitted by germinating barley seeds was higher in 'seed-to-seed' than in 'seed-after-seed' experimental protocols and the difference was highly significant for both tested weed species, B. diandrus and L. rigidum. The originality of the 'seed-after-seed' method is twofold. First it reduces the competition effect as the donor and receiver species are grown sequentially and do not compete for resources at the same time in the same growing media. Second, the 'seed-after-seed' protocol 
excludes the action of VOCs which might intervene when both the donor and the receiver plants are grown together in the same closed container. As the receiver plants are placed in the container after removal of the donor plants, the atmosphere of the container is 'reset' and any allelopathic effect should then be ascribed to water-soluble compounds, released by the donor or those resulting from their degradation. When comparing the 'seed-to-seed' and 'seed-after-seed' effects, a third element should be taken into account, which is the possible time-course evolution of the allelochemicals after their release by the donor. These changes can be described in quantitative terms, i.e. the decay of the released allelochemicals over time, and in qualitative terms, resulting from the production of new compounds with possibly higher or lower allelopathic activities.

The two experimental protocols used in this study showed that allelochemicals of barley seedlings reduced both radicle and coleoptile lengths of $B$. diandrus and $L$. rigidum as compared to the control, after five days of growth. This effect was dependent on the density of barley seeds and was shown to be more pronounced on roots (Figs. 1, 2, 3, 4). In fact, roots are considered as particularly susceptible to allelochemicals (Wu et al. 2000a). Roots might be the primary target as they are in direct contact with the exuded allelochemicals (Viard-Crétat et al. 2009).

Based on the 'seed-after-seed' protocol, the barley varieties and landraces exhibited a differential allelopathic activity against weeds (Figs. 3, 4). Variation in allelopathic activity was also reported in different barley germoplasms (Baghestani et al. 1999; Bertholdsson 2004; Oveisi et al. 2008; Vasilakoglou et al. 2009). Interestingly, in our study, the Tunisian barley landraces, 'Ardhaoui' and 'Arbi', showed the highest inhibitory effects. This might indicate a change in the ability to secrete allelochemicals as a result of the breeding of modern barley cultivars, but the low number of genotypes used in our study does not allow any definitive conclusions in this regard. Bertholdsson (2004) found a decreasing trend in allelopathic activity in Swedish and Finnish barley germplasm between the periods of 1890 to 2003, with the introduction of new cultivars. This author assumed that more than 100 years of selection and breeding have reduced the frequency of the genes from landraces conferring the allelopathic ability.

However, it is worth noting that our study showed that 'Rihane', a modern and the most cultivated barley variety in Tunisia (Degha'is et al. 1999), has an allelopathic activity similar to that of the landraces, at least under the tested conditions showing in vitro inhibition of weed development by allelochemicals produced by young barley seedlings.

On the other hand, the two weeds seemed to respond to the allelopathic effect of barley in a similar way, although $B$. diandrus was marginally more susceptible in comparison to $L$. rigidum. The response seems to be independent of the seed size (10.4 and $2.55 \mathrm{mg}$ for the dry seed mass of B. diandrus and L. rigidum, respectively), in contrast with Petersen et al.'s (2001) proposing that species with smaller seeds like spiny sowthistle seeds ( $0.2 \mathrm{~g}$ for the thousand seed mass) are generally more sensitive than larger seeded species like wheat seeds ( $45.3 \mathrm{~g}$ for the thousand seed mass).

The present research also showed that barley root allelochemicals cause some autotoxicity. Genotypic variation was also observed at that level, with 'Arbi' and 'Ardhaoui' being more autotoxic than 'Manel' and 'Tej'. Evidence of autotoxicity was first documented by Ben-Hammouda et al. (2002) using a water extract of Tunisian barley residues from roots, stems and leaves obtained from mature plants developed in the field. He found that 'Manel' was the most susceptible cultivar to the water extract of 'Rihane' residues. Oueslati et al. (2005) reported that radicle growth in 'Manel' was significantly reduced after 2.5 days, by 50 and $60 \%$ when using 'Rihane' and 'Manel' water extracts respectively. However, in our study, this variety is the least inhibited by its own radicle exudates. This suggests that barley growth might be affected to different extents by allelochemicals released from residues of mature plants and from young living plant tissues, as reported by Overland (1966).

Compared to its alloinhibition activity on the two tested weed species, the autoinhibition of barley was much lower. Despite the fact that all belong to the same family (Poaceae), the inhibitory action of barley was shown to be discriminant with respect to the various tested plants. Such discrimination has been reported in other allelopathic systems, like the water-soluble saponins of alfalfa reported to exhibit allelopathic effects on other plants with no evidence for autotoxic effects (Miller 1983).

Our study of the toxicity of barley allelochemicals showed that they were more toxic over time and that this increase in inhibition was more pronounced with coleoptiles than with roots, in both weed species. Therefore, we conclude that the higher growth inhibition observed in the 'seed-to-seed' protocol, compared with the 'seed-afterseed' one, cannot be due to a decrease of toxicity of the released allelochemicals over time, but could be due to the additional effects of some volatile allelochemicals and of resource (water) competition, when barley and 
weed seeds are placed together in such a closed environment.

The increased toxicity of the released allelochemicals was probably due to their chemical modification. Gagliardo and Chilton (1992) reported a higher phytotoxicity in barnyard grass of the microbially-degraded product of rye allelochemical, 2-amino-3H-phenoxazin-3-one than its precursor 2-benzoxazoli-none (BOA). Maclas et al. (2003) showed also that wheat coleoptiles were highly susceptible to the BOA derived from the hydroxamic acid DIBOA (2, 4-dihydroxy-1,4-benzoxazin-3-one) of wheat in non sterile soil. Allelopathic effects can be altered by the metabolization of allelochemicals by soil microbes into new products with enhanced or reduced toxicity (Inderjit 2005), but microbial action does not seem to be the unique cause of the biodegradation of allelochemicals. Indeed, the phytotoxicity of these molecules can be influenced by both abiotic (physical and chemical) and biotic (microbial) factors (Inderjit 2001).

Based on the absence of the DIBOA compound in cultivated barley (Barria et al. 1992; Gianoli and Niemeyer 1998; Grün et al. 2005), the allelochemical of which biodegradation was the most studied in wheat, we hypothesize that barley releases different molecules changing over time. Further work is needed to identify the allelochemicals released by barley roots and their fate in the environment. Why barley is less susceptible to its own allelochemicals than other grass species is also a question deserving further investigation. Answers to these questions are important for the future exploitation of allelopathy in innovative and sustainable weed control strategies.

\section{Acknowledgments}

During this work, the first author was recipient of a PhD fellowship of the Erasmus Mundus Averroès Partnerships Action of the European Commission. We would like to thank François Rochet for her valuable help in statistical analysis. This work was funded by internal grants of Gembloux-Agro Bio Tech, University of Liège, Belgium.

\section{References}

Baghestani A, Lemieux C, Leroux GD, Baziramakenga R (1999) Determination of allelochemicals in spring cereal cultivars of different competitiveness. Weed Sci 47:498-504

Barria BN, Copaja SV, Niemeyer HM (1992) Occurrence of DIBOA in wild Hordeum species and its relation to aphid resistance. Phytochemistry 31:89-91

Ben Haj Salah H, Kilani H, Souissi T, Latiri K, Dahmane ABK (2005) Etude de la biologie du grand brome (Bromus diandnis Roth.) : Cycle de développement du brome seul et en association avec le blé. Revue de L'INAT 20(2):35-49

Ben-Hammouda M, Kremer RJ, Minor HC, Sarwar M (1995) A chemical basis for differential allelopathic potential of sorghum hybrids on wheat. J Chem Ecol 21:775-786

Ben-Hammouda M, Ghorbal H, Kremer RJ, Oueslati O (2002) Autotoxicity of barley. J Plant Nutr 25:1155-1161

Bertholdsson NO (2004) Variation in allelopathic activity over 100 years of barley selection and breeding. Weed Res 44:78-86

Chon SU, Kim YM (2004) Herbicidal potential and quantification of suspected allelochemicals from four grass crop extracts. J Agron Crop Sci 190:145-150

Deghai's M, El Felah M, Gharbi MS, Zarkouna T, Chakroun M (1999) Les acquis de l'amélioration génétique des céréales en Tunisie. Annales de l'INTRAT 72:21-27

Fiers M, Lognay G, Fauconnier ML, Jijakli MM (2013) Volatile compound-mediated interactions between barley and pathogenic fungi in the soil. PLoS ONE 8(6): 1-18

Fuerst ER, Putnam AR (1983) Separating the competitive and allelopathic components of interference: theoretical principles. J Chem Ecol 9:937-944

Fujii Y (2001) Screening and future exploitation of allelopathic plant as alternative herbicides with special reference to hairy vetch. J Crop Prot 4:257-275 
Gagliardo RW, Chilton WS (1992) Soil transformation of 2(3H)-benzoxazolone of rye into phytotoxic 2-amino-3H-phenoxazin-3-one. J Chem Ecol 18:1683-1691

Gasquez J (2000) Extension des graminées adventices résistantes aux antigraminées foliaires en France. In: Proceedings of the XI international conference on weed biology. Association Française de Protection des Plantes, Dijon, France, pp 485-492

Gfeller A, Laloux M, Barsics F, Kati DE, Haubruge E, du Jardin P, Verheggen FJ, Lognay G, Wathelet JP, Fauconnier ML (2013) Characterization of volatile organic compounds emitted by barley (Hordeum vulgare L.) roots and their attractiveness to wireworms. J Chem Ecol 39:1129-1139

Gianoli E, Niemeyer HM (1998) DIBOA in wild Poaceae: sources of resistance to the Russian wheat aphid (Diuraphis noxia) and the greenbug (Schizaphis graminum). Euphytica 102:317-321

Grün S, Frey M, Gierl A (2005) Evolution of the indole alkaloid biosynthesis in the genus Hordeum: distribution of gramine and DIBOA and isolation of the benzoxazinoid biosynthesis genes from Hordeum lechleri. Phytochemistry 66:1264-1272

Gubbels GH, Kenaschuk EO (1989) Agronomic performance of flax grown on canola, barley and flax stubble with and without tillage prior to seeding. Can J Plant Sci 69:31-38

Hoult AHC, Lovett JV (1993) Biologically active secondary metabolites of barley. III. A method for identification and quantification of hordenine and gramine in barley by high-performance liquid chromatography. J Chem Ecol 19:2245-2254

Inderjit S (2001) Soil: environmental effects on allelochemical activity. Agron J 93:79-84

Inderjit S (2005) Soil microorganisms: an important determinant of allelopathic activity. Plant Soil 274:227-236

Kellner M, Kolodinska Brantestam A, Ahman I, Ninkovic V (2010) Plant volatile-induced aphid resistance in barley cultivars is related to cultivar age. Theor Appl Genet 121:1133-1139

Kremer R, Ben-Hammouda M (2009) Allelopathic plants. 19. Barley (Hordeum vulgare L.). Allelopath J 24(2):225-242

Kushima M, Kakuta H, Kosemura S, Yamamura S, Yamada K, Yokotani-Tomita K, Hasegawa K (1998) An allelopathic substance exuded from germinating watermelon seeds. Plant Growth Regul 25:1-4

Lanoue A, Burlat V, Henkes GJ, Koch I, Schurr U, Röse USR (2010) De novo biosynthesis of defense root exudates in response to Fusarium attack in barley. New Phytol 185:577-588

Laterra P, Bazzalo ME (1999) Seed-to-seed allelopathic effects between two invaders of burned Pampa grasslands. Weed Res 39:297-308

Liu DL, Lovett JV (1993a) Biologically active secondary metabolites of barley. I. Developing techniques and assessing allelopathy in barley. J Chem Ecol 19:2217-2230

Liu DL, Lovett JV (1993b) Biologically active secondary metabolites of barley. II. Phytotoxicity of barley allelochemicals. J Chem Ecol $19: 2231-2244$

Lodhi MAK, Bilal R, Malik KA (1987) Allelopathy in agro-ecosystems: wheat phytotoxicity and its possible role in crop rotation. J Chem Ecol 13:1881-1891

Ma SY, Kim JS, Ryang HS (1999) Allelopathic effect of barley to red rice and barnyardgrass. Korean J Weed Sci 19:228-235

Macias FA, Marin D, Oliveros-Bastidas A, Varela RM, Simonet AM, Carrera C, Molinillo JM (2003) Allelopathy as a new strategy for sustainable ecosystems development. Biol Sci Space 17(1): 18-23

Mason HE, Spaner D (2006) Competitive ability of wheat in conventional and organic management systems: a review of the literature. Can J Plant Sci 86:333-343

Miller DA (1983) Allelopathic effects of alfalfa. J Chem Ecol 9:1059-1072

Nilsson MC (1994) Separation of allelopathy and resource competition by the boreal dwarf shrub Empetrum hermaphroditum Hagerup. Oecologia $98: 1-7$

Ninkovic V (2003) Volatile communication between barley plants affects biomass allocation. J Exp Bot 54(389):1931-1939

Olofsdotter M, Navarez M, Rebulanan M, Streibig JC (1999) Weed-suppressing rice cultivars-does allelopathy play a role? Weed Res 39:441-454

Oueslati O, Ben-Hammouda M, Ghorbal MH, El Gazzeh M, Kremer RJ (2005) Barley autotoxicity as influenced by varietal and seasonal variation. J Agron Crop Sci 191:249-254 
Oveisi M, Mashhadi HR, Baghestani MA, Alizadeh HM, Badri S (2008) Assessment of the allelopathic potential of 17 Iranian barley cultivars in different development stages and their variations over 60 years of selection. Weed Biol Manag 8:225-232

Overland L (1966) The role of allelopathic substances in the 'smother crop' barley. Am J Bot 53:423-432

Petersen J, Belz R, Walker F, Hurle K (2001) Weed suppression by release of isothiocyanates from turnip-rape mulch. Agron J 93:37-43

Putnam AR (1985) Allelopathic research in agriculture: past highlights and potential. In: Thompson AC (ed) The chemistry of allelopathy: biochemical interactions among plants. American Chemical Society, Washington, USA, pp1-8

Qasem JR, Hill TA (1989) On difficulties with allelopathy methodology. Weed Res 29:345-347

Rice EL (1984) Allelopathy, 2nd edn. Academic Press, Orlando, USA

Ridenour WM, Callaway RM (2001) The relative importance of allelopathy in interference: the effects of an invasive weed on a native bunchgrass. Oecologia 126:444-450

Souissi T, Belhadjsalah H, Mhafdhi M, Latiri K (2000) Non chemical control of Bromus diandrus Roth, in wheat in Tunisia. In: Proceedings of the XI International Conference on Weed Biology. Association Française de Protection des Plantes, Dijon, France, pp 417-424

Souissi T, BelhadjSalah H, Latiri K (2001) Brome in cereal crops: infestations and management. L'Investisseur Agricole 42:29-32

Souissi T, Labidi S, Ben Hadj Salah H (2004) Mise en évidence et origine de la résistance herbicide aux raygrass (Lolium rigidum Gaud.) dans les cultures de blé. Revue de L'INAT 19(1):149-161

Vasilakoglou I, Dhima K, Lithourgidis A, Eleftherohorinos I (2009) Allelopathic potential of 50 barley cultivars and the herbicidal effects of barley extract. Allelopath J 24(2):309-320

Viard-Crétat F, Gallet C, Lefebvre M, Lavorel S (2009) A leachate a day keeps the seedlings away: mowing and the inhibitory effects of Festuca paniculata in subalpine grasslands. Ann Bot 103:1271-1278

Weidenhamer JD (1996) Distinguishing resource competition and chemical interference: overcoming the methodological impasse. Agron J 88:866-875

Wu H, Haig T, Prately J, Lemerle D, Lemerle D, An M (2000a) Distribution and exudation of allelochemicals in wheat Triticum aestivum. J Chem Ecol 26:2141-2154

Wu H, Prately J, Lemerle D, Haig T (2000b) Evaluation of seedling allelopathy in 453 wheat (Triticum aestivum) accessions against annual ryegrass (Lolium rigidum) by the equal-compartment-agar method. Aust J Agric Res 51:937-944

Zhang S, Liu J, Bao X, Niu K (2011) Seed-to-seed potential allelopathic effects between Ligularia virgaurea and native grass species of Tibetan alpine grasslands. Ecol Res 26:47-52

Imen Bouhaouel is a $\mathrm{PhD}$ student interested in the study of allelopathy-plant interactions and identification of allelochemicals.

Aurélie Gfeller was a post-doctoral researcher in Gembloux Agro-Bio Tech (2010) characterized the VOCs emitted by barley root. Now, she is a researcher in Agroscope AC and interested by the allelopathic interactions between cover crops and weeds.

Marie-Laure Fauconnier is a professor in general and organic chemistry. She's the coordinator of the Rhizovol project aimed to study the role of VOCs emitted by barley roots in different biotic interaction contexts.

Salah Rezgui is a professor in agriculture sciences and implemented biometrical models.

Hajer Slim Amara is a professor in genetics and plant breeding. Her research is focused on the improvement of plants against stress.

Patrick du Jardin is a professor in plant biology. His research is focused on the physiology of plants and the exploitation of biotechnological tools in this perspective. 